\title{
Structural studies on ruthenium(II) complexes used in interphase catalysis for the hydrogenation of ketones
}

\author{
Venkata Krishnan ${ }^{\dagger}{ }^{\dagger}$ and Helmut Bertagnolli \\ Institute of Physical Chemistry, University of Stuttgart, Pfaffenwaldring 55, 70569 Stuttgart, Germany
}

Received 27 November 2006; Accepted 27 November 2006

\begin{abstract}
Structural studies were performed on catalytically active ruthenium(II) complexes used in interphases, by means of XAFS spectroscopy. The EXAFS investigations indicate that the complexes retain their structural integrity when they are embedded on polysiloxane matrices to form stationary phase materials. The AXAFS studies reveal that the variations in the catalytic activity of the complexes with different ligands can be correlated to the differences in the electronic structure around the active ruthenium center. The EXAFS investigations show that, in asymmetric transfer hydrogenation reactions catalysed by ruthenium(II) complexes, the co-catalyst plays a crucial role not only in enhancing the catalytic activity, but also in determining the structure of the intermediate species. Copyright $\odot 2007$ John Wiley \& Sons, Ltd.
\end{abstract}

KEYWORDS: ruthenium complexes; catalysis, EXAFS; AXAFS; co-catalyst

\section{INTRODUCTION}

Interphase catalysis has gained great importance in recent years due to its ability to combine the advantages of homogeneous and heterogeneous catalysis with a remarkable decrease of drawbacks like leaching and reduced catalytic activity of the reactive center. ${ }^{1,2}$ Interphases are systems in which a stationary phase (comprising active centers, polymer and spacer) and a mobile component (gas, liquid or dissolved reactants) penetrate each other on a molecular scale without forming a homogeneous phase. When such interphases are provided with a swellable polymer, they will be able to imitate homogeneous conditions as the active centers become highly mobile, simulating the properties of a solution. ${ }^{3}$ In such systems, the catalysts are easily separable from the reaction products and can be used for several cycles. ${ }^{4}$ The density of the active centers can be influenced by co-condensates, which are applied in the form of multi-functionalized siloxanes. These co-condensates enlarge the space between the active metal center and the carrier matrix, thereby improving the accessibility of the catalytically active reaction center.

* Correspondence to: Venkata Krishnan, Institute of Physical Chemistry, University of Stuttgart, Pfaffenwaldring 55, 70569 Stuttgart, Germany.

E-mail: v.krishnan@ipc.uni-stuttgart.de

${ }^{+}$Current address: Department of Chemistry, University of Pennsylvania, 231 South 34th Street, Philadelphia, PA 19104, USA.

Contract/grant sponsor: Deutsche Forschungsgemeinschaft.
Transition metal complexes are increasingly used for different industrially important catalytic reactions such as asymmetric hydrogenation catalysis, stereoselective catalysis etc. ${ }^{5,6}$ Ruthenium(II) complex system containing diphosphine and 1,2-diamine ligands proved to be excellent catalysts for the hydrogenation of ketones, in the presence of a base and 2-propanol, under mild conditions. ${ }^{7,8}$ Subsequently, several chiral ruthenium(II) complexes were developed for asymmetric hydrogenation of functionalized ketones. ${ }^{9,10}$ Embedding these complexes in polymer matrices avoids leaching, while the activity and enantioselectivity remain unaltered. ${ }^{11}$ The catalytic activity is traced back to the electronic properties of the coordination center and the stereoselectivity is controlled by the chiral ligand. ${ }^{12}$

An important condition for the optimization of the interphases is the exact knowledge of the structural correlation between each of the different components in such systems. In this context, the local environment around the metal atom, which represents the active center in the interphase systems, plays a decisive role. Owing to the disordered nature of the stationary phase, it is not possible to obtain structural information using the conventional X-ray diffraction methods. Hence, the local structure and the coordination geometry around the central metal atom must be determined by other methods that are able to answer the question of structural integrity of the embedded complexes. Among these methods, extended X-ray absorption 
fine structure (EXAFS) spectroscopy is a powerful technique for probing the neighborhood environment of a selected atom regardless of the physical state of the sample and provides information on the coordination number, the nature of the scattering atoms surrounding the absorbing atom, the interatomic distance between the absorbing atom and the backscattering atoms, and the Debye-Waller factor, which accounts for the static disorders and thermal vibrations. ${ }^{13,14}$

Another vital aspect in the interphase systems is the study of electronic properties of the active metal center, which is influenced by the coordinating ligands. Atomic $X$-ray absorption fine structure (AXAFS) spectroscopy is a sensitive tool to study the charge densities that are responsible for bonding and to determine the electronic structure of the metal center. AXAFS arises from scattering within the absorbing atom due to the backscattering of the photoelectron at charge densities around the absorbing atom. This extrafine structure originates from resonant scattering in the periphery of the absorbing atom. ${ }^{15}$ AXAFS occurs very near to the absorption edge and the oscillatory structure is analogous to that occurring from neighboring atoms. The intensity and position of the AXAFS features is a function of the bonding of the absorbing atom with its environment. ${ }^{16}$

Among the interphase catalysis reactions, the asymmetric transfer hydrogenation of prochiral ketones is one of the most attractive methods for the access of optically active secondary alcohols, which form an important class of intermediates for fine chemical and pharmaceutical industries. Ever since the discovery of the Meerwein-Ponndorf-Verley reaction, in which a ketone is reduced to an alcohol in the presence of aluminum alkoxide, co-catalysts have been widely used for the promotion of the catalytic activity of metal complex catalysts. ${ }^{10}$ The addition of a co-catalyst like alkali metal hydroxides/alkoxides to the complex dissolved in a secondary alcohol has emerged as an important issue in the hydrogenation process. The role of the co-catalyst in determining the catalytic activity of this hydrogenation reaction has been reported in literature, ${ }^{17}$ where the researchers have shown the importance of the alkali metal cation in the metal alkoxide co-catalysts. Furthermore, they demonstrated that the alkali metal cations affect the activity in the order $\mathrm{K}>\mathrm{Na} \approx \mathrm{Rb}>\mathrm{Li}$ and an increase in the alkali metal cation concentration with a constant amount of base enhances the catalytic activity. Several researchers have recently evidenced that the bifunctional cis-oriented $\mathrm{Ru}-\mathrm{H} / \mathrm{N}-\mathrm{H}$ motif plays a key role in the hydrogenation of unsaturated ketones. .,12,18 $^{2}$

In this article, we present the structural investigations on embedded ruthenium(II) complexes, performed by means of EXAFS spectroscopy. We also report the AXAFS spectroscopic investigations performed on ruthenium(II) complexes with different ligands and discuss the correlation between their electronic structure and catalytic activity. In order to elucidate the role of the bifunctional cis-oriented $\mathrm{Ru}-\mathrm{H} / \mathrm{N}-\mathrm{H}$ motif and the function of the co-catalyst in the hydrogenation of unsaturated ketones, we studied the influence of the co-catalyst on the structure of catalytic intermediate species in the asymmetric transfer hydrogenation reaction by ruthenium(II) complexes. Owing to the reasons mentioned above, the cocatalyst ${ }^{t} \mathrm{BuOK}$ was chosen for the present investigations.

\section{EXPERIMENTAL}

\section{Sample preparation}

The different monomeric ruthenium(II) complexes containing diamine(diphosphine) and diamine(ether-phosphine) ligands were synthesized using the procedure described in the literature and were found to be highly catalytically active in the hydrogenation of $\alpha, \beta$-unsaturated ketones. ${ }^{19,20}$ The embedded complexes were prepared on the basis of a surfactant-templated sol-gel method with the monomer complex and tetramethoxysilane (TMOS) in the ratio $1: 10 .^{21-24}$

\section{XAFS measurements}

The transmission mode X-ray absorption fine structure (XAFS) measurements of the samples were performed at the $\mathrm{Ru}$ K-edge at $22117 \mathrm{eV}$ at the beamline X1.1 of the Hamburger synchrotron radiation laboratory (HASYLAB) at DESY, Hamburg. The samples were measured with Si(311) double crystal monochromator at ambient conditions and ion chambers filled with argon were used to measure the incident and transmitted intensities. The positron energy was $4.45 \mathrm{GeV}$ and the beam current was between 90 and $130 \mathrm{~mA}$ during the measurements. The concentration of the samples was adjusted to yield an extinction of 1.5.

\section{EXAFS evaluation}

In the data analysis, the program WINXAS ${ }^{25}$ was used for normalisation and the program $\mathrm{AUTOBK}^{26}$ was used for the removal of background. The employed method subtracts a spline that best eliminates the non-structural portion from the measured spectrum. The spline used to approximate the background is a third-order polynomial spline with knots that are equally spaced in $k$-space, where one degree of freedom in the spline is allowed. Data evaluation in $k$-space was performed according to the curved wave formalism of the program EXCURV $92^{27}$ with XALPHA phase and amplitude functions. The mean free path of the scattered electrons was calculated from the imaginary part of the potential (VPI set to -4.00 ), the amplitude factor AFAC was fixed at 0.8 and an overall energy shift $\Delta E_{0}$ was introduced to give a best fit to the data. The structural parameters were obtained by nonlinear least squares fitting in $k$-space with $k^{3}$ weighting, and with $k$-ranges chosen to be as large as possible. In the fitting procedure, the interatomic distances, Debye-Waller factors and energy zero value were determined by iterations. The coordination numbers were iterated and then fixed to the nearest possible integer values.

\section{AXAFS evaluation}

The AXAFS features arise from the difference between the free atom potential and the absorbing atom potential. The 
objective is to remove the contributions due to unbound absorbing atom and consider only those from the absorbing atom bound to its neighbors. The AXAFS contributions may overlap with the multiple electron excitations (MEE) and Ramsauer-Townsend resonances (RTR) at the low $r$-ranges, and with EXAFS oscillations at the high $r$-ranges. Hence, both these features need to be separated from the AXAFS signals. For this purpose, the criterion used for the background removal, outlined in literature, ${ }^{28}$ was employed. The program AUTOBK $^{26}$ was used for the AXAFS background removal as well. Calculations were performed with different sets of $r_{\mathrm{bkg}}$ (refers to the upper limit of the low $r$-region over which the background is to be fit) values on a specific sample, namely, diphenyl(ether-phosphine) ruthenium(II) complex and the best $r_{\mathrm{bkg}}$ value was selected. The chosen value was used in the isolation of background from the AXAFS signal for all the other samples. It is always possible that the choice of the $r_{\text {bkg }}$ value does not lead to an optimal separation between MEE, AXAFS and EXAFS. However, it should be noted that, even without an optimal background subtraction, identical trends in the final AXAFS data could still be found as long as the background subtraction is performed consistently. ${ }^{29}$ The final trend in the AXAFS areas will be the same, even though the absolute areas may be different. The data analysis in $k$ space was performed using curved wave theory with XALPHA phase and amplitude functions and the resulting $\chi(k)$ function was weighed with $k^{1}$.

\section{RESULTS AND DISCUSSION}

\section{Monomeric and embedded complexes}

As a representative example, three embedded complexes studied by means of EXAFS spectroscopy are presented here along with their corresponding monomeric counterparts. The structure of the different complexes investigated in the present work is depicted in Fig. 1. The experimentally determined and theoretically calculated EXAFS functions in $k$-space and their Fourier transforms in real space for the different monomeric and embedded complexes, measured at
Ru K-edge, are shown in Figs 2-4. The obtained structural parameters are tabulated in Table 1.

In all the cases, the $k^{3}$-weighted EXAFS function could be best described by a three-shell model. The first shell consisting of two nitrogen backscatterers arising from the diamine ligand is found at $2.18 \AA$ distance, the second shell having two phosphorous backscatterers stemming from the phosphine ligand is determined at $2.29 \AA$ distance in ether-phosphine complexes (1 and 2) and $2.26 \AA$ distance in diphosphine complex (3). The only difference in the diamine(etherphosphine) ruthenium(II) complex (2) in comparison to the diamine(diphosphine) ruthenium(II) complex (3) is that the two phosphorus atoms are not rigidly connected through the carbon atom, but connected to the oxygen atom through carbon atoms. As a consequence, a slight lengthening of the ruthenium-phosphorus bond could be observed in the case of diamine(ether-phosphine) ruthenium(II) complex (2). In addition, the third shell comprising of two chlorine backscatterers is determined at $2.41 \AA$ distance in all the complexes. The results obtained for the monomeric complexes are in good agreement with the values determined using single crystal X-ray diffraction. ${ }^{19,20}$ The EXAFS results reveal that the complexes retain their structure even when they are embedded in TMOS.

\section{AXAFS investigations}

AXAFS represents the scattering from the potential of the electron cloud of the absorber atom itself. The potential is dependent on the chemical and electronic environment of the absorbing atom and can be influenced by the different ligands. As the catalytic activity was observed to be different for the complexes with different ligands, ${ }^{19,20}$ AXAFS investigations were performed on three selected complexes, which have the same coordination environment around the ruthenium nucleus but with different ligands, as shown in Fig. 5. The investigations are aimed at studying the influence of the different ligands on the electronic structure of the obtained ruthenium(II) complexes. The AXAFS signal was isolated from total XAFS, by subtracting the fitted EXAFS contribution from the experimental spectrum using the procedure

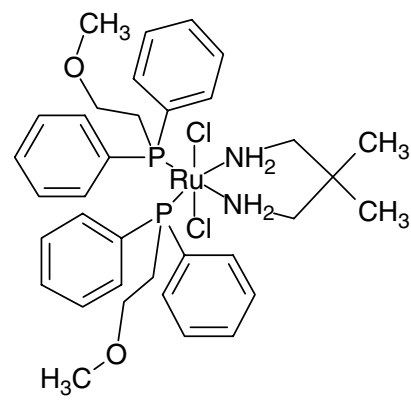

1

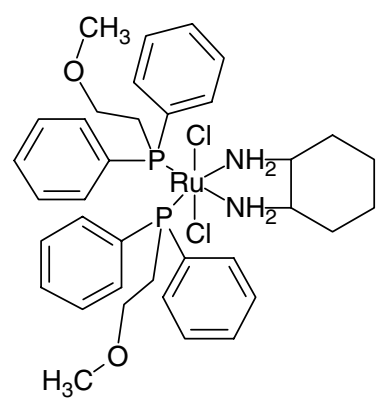

2

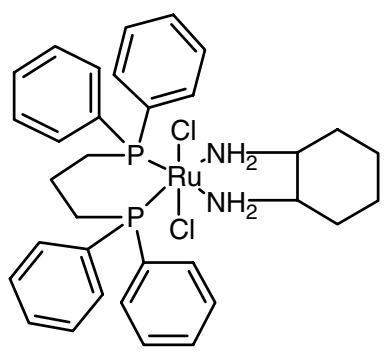

3

Figure 1. Structure of ruthenium(II) complexes $\mathbf{1 , 2}$ and $\mathbf{3}$. 

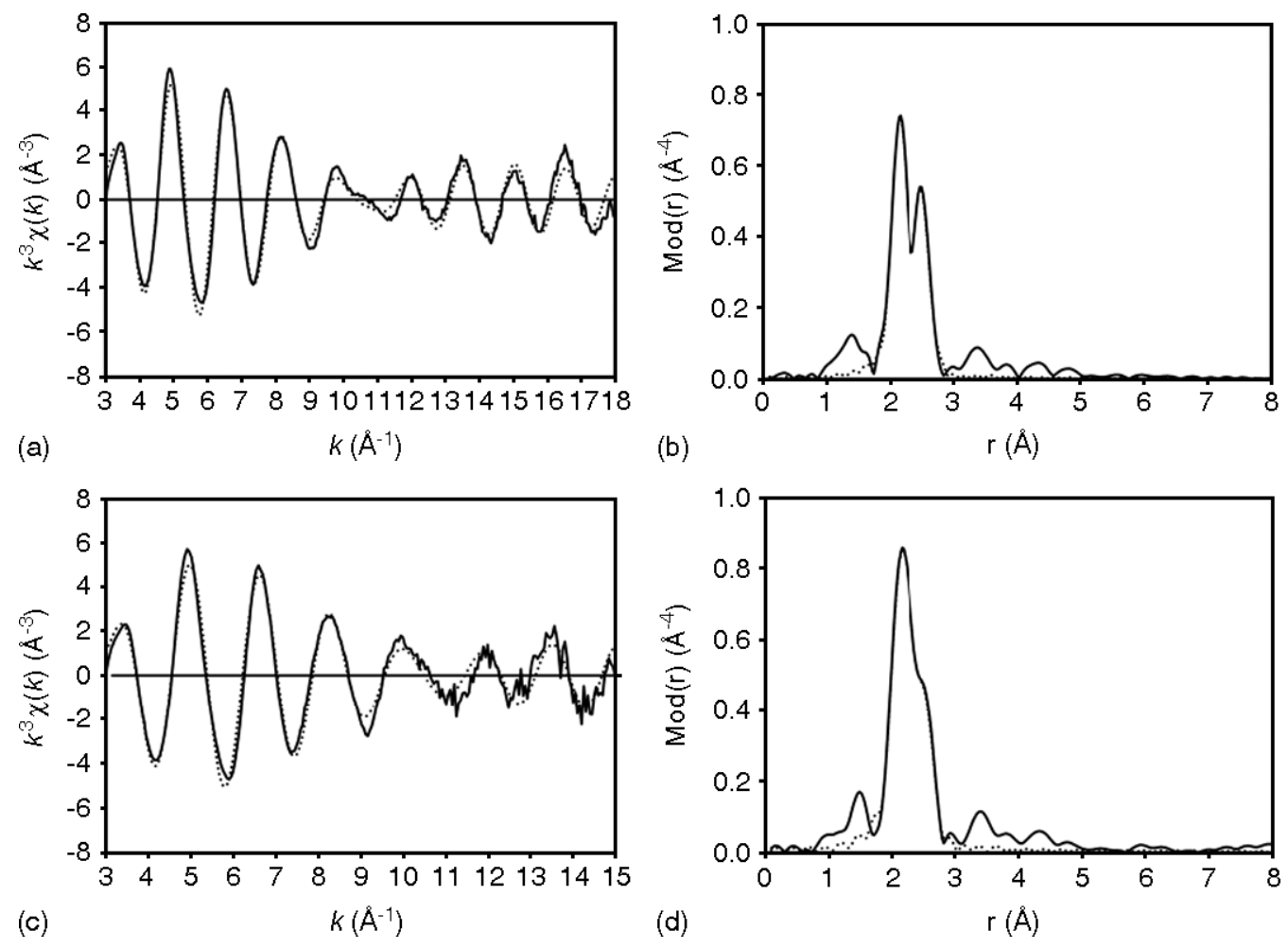

Figure 2. Experimental (solid line) and calculated (dotted line) EXAFS functions and their Fourier transforms for monomeric complex 1 (a and b) and for complex 1, embedded in TMOS (c and d).
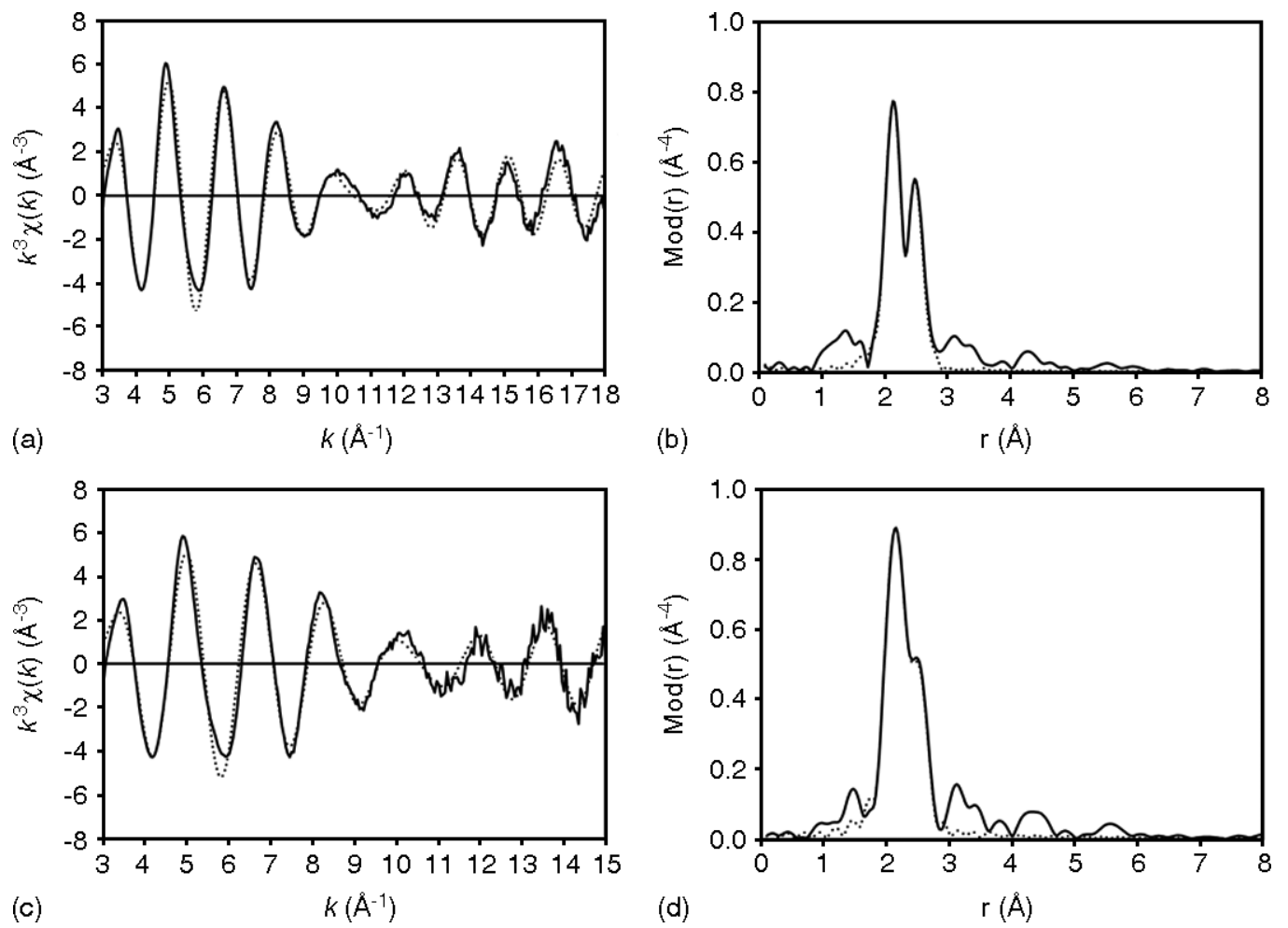

Figure 3. Experimental (solid line) and calculated (dotted line) EXAFS functions and their Fourier transforms for monomeric complex 2 (a and b) and for complex 2, embedded in TMOS (c and d). 

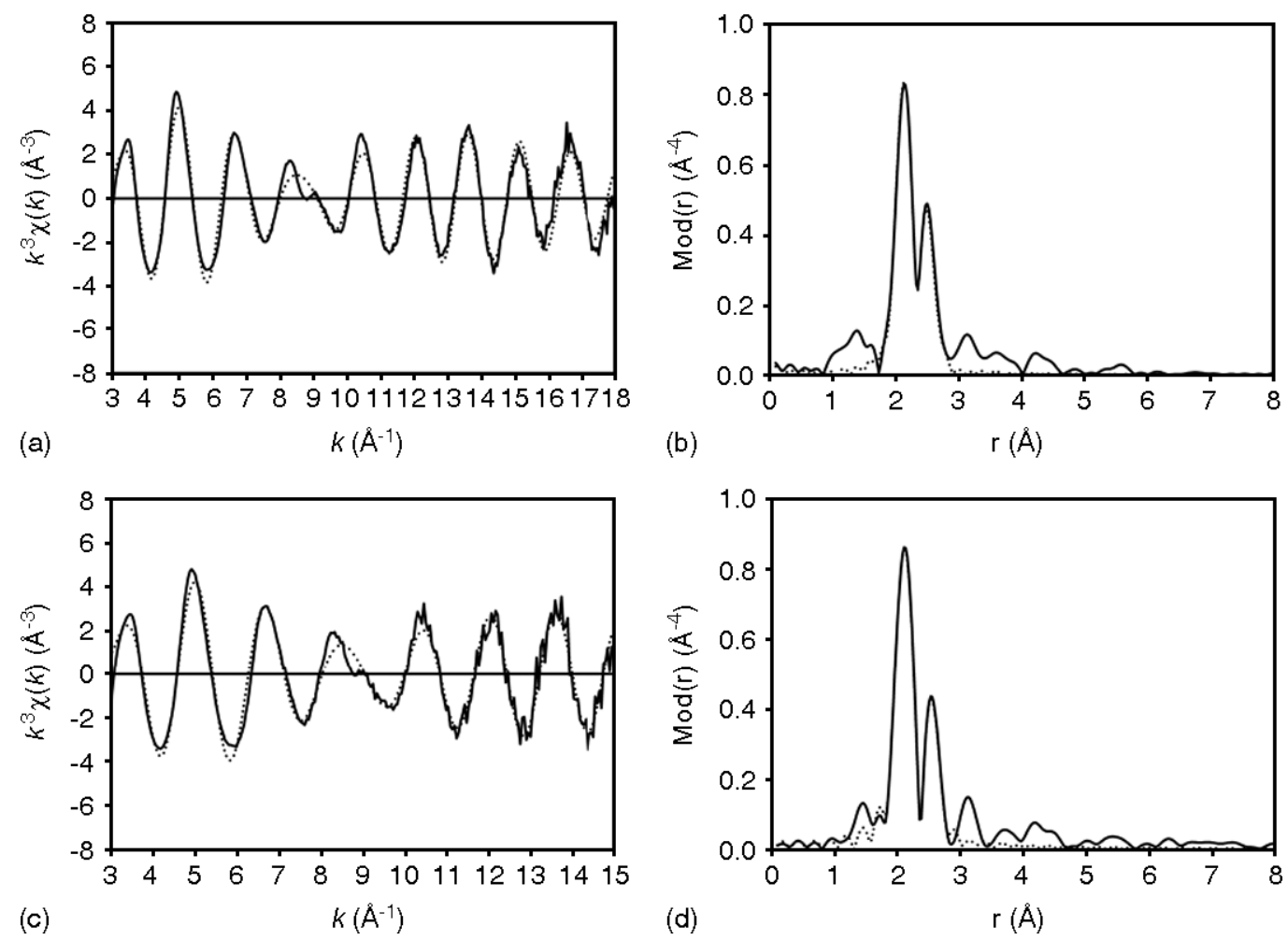

Figure 4. Experimental (solid line) and calculated (dotted line) EXAFS functions and their Fourier transforms for monomeric complex 3 (a and b) and for complex $\mathbf{3}$, embedded in TMOS (c and d).

Table 1. EXAFS determined structural parameters for monomeric and embedded ruthenium(II) complexes

\begin{tabular}{|c|c|c|c|c|c|c|c|c|}
\hline Complex & Case & $\mathrm{A}-\mathrm{Bs}^{\mathrm{a}}$ & $N^{b}$ & $r^{c}[\AA]$ & $\sigma^{\mathrm{d}}[\AA]$ & $\Delta E_{0}{ }^{\mathrm{e}}[\mathrm{eV}]$ & $k$-range $\left[\AA^{-1}\right]$ & $R$-factor \\
\hline \multirow[t]{6}{*}{1} & \multirow[t]{3}{*}{ Monomer } & $\mathrm{Ru}-\mathrm{N}$ & 2 & $2.18 \pm 0.02$ & $0.050 \pm 0.005$ & \multirow{3}{*}{21.57} & \multirow[t]{3}{*}{$3.0-18.0$} & \multirow[t]{3}{*}{21.88} \\
\hline & & $\mathrm{Ru}-\mathrm{P}$ & 2 & $2.29 \pm 0.02$ & $0.069 \pm 0.007$ & & & \\
\hline & & $\mathrm{Ru}-\mathrm{Cl}$ & 2 & $2.42 \pm 0.02$ & $0.061 \pm 0.006$ & & & \\
\hline & \multirow[t]{3}{*}{ Embedded } & $\mathrm{Ru}-\mathrm{N}$ & 2 & $2.18 \pm 0.02$ & $0.059 \pm 0.006$ & \multirow[t]{3}{*}{21.28} & \multirow[t]{3}{*}{$3.0-15.0$} & \multirow[t]{3}{*}{23.05} \\
\hline & & $\mathrm{Ru}-\mathrm{P}$ & 2 & $2.28 \pm 0.02$ & $0.059 \pm 0.006$ & & & \\
\hline & & $\mathrm{Ru}-\mathrm{Cl}$ & 2 & $2.40 \pm 0.03$ & $0.067 \pm 0.008$ & & & \\
\hline \multirow[t]{6}{*}{2} & \multirow[t]{3}{*}{ Monomer } & $\mathrm{Ru}-\mathrm{N}$ & 2 & $2.18 \pm 0.02$ & $0.050 \pm 0.005$ & \multirow[t]{3}{*}{22.07} & \multirow[t]{3}{*}{$3.0-18.0$} & \multirow[t]{3}{*}{25.03} \\
\hline & & $\mathrm{Ru}-\mathrm{P}$ & 2 & $2.28 \pm 0.02$ & $0.062 \pm 0.006$ & & & \\
\hline & & $\mathrm{Ru}-\mathrm{Cl}$ & 2 & $2.41 \pm 0.02$ & $0.058 \pm 0.006$ & & & \\
\hline & \multirow[t]{3}{*}{ Embedded } & $\mathrm{Ru}-\mathrm{N}$ & 2 & $2.18 \pm 0.02$ & $0.067 \pm 0.007$ & \multirow[t]{3}{*}{22.65} & \multirow[t]{3}{*}{$3.0-15.0$} & \multirow[t]{3}{*}{25.41} \\
\hline & & $\mathrm{Ru}-\mathrm{P}$ & 2 & $2.28 \pm 0.02$ & $0.050 \pm 0.005$ & & & \\
\hline & & $\mathrm{Ru}-\mathrm{Cl}$ & 2 & $2.40 \pm 0.03$ & $0.059 \pm 0.007$ & & & \\
\hline \multirow[t]{6}{*}{3} & \multirow[t]{3}{*}{ Monomer } & $\mathrm{Ru}-\mathrm{N}$ & 2 & $2.19 \pm 0.02$ & $0.064 \pm 0.006$ & \multirow[t]{3}{*}{22.66} & \multirow[t]{3}{*}{$3.0-18.0$} & \multirow[t]{3}{*}{23.07} \\
\hline & & $\mathrm{Ru}-\mathrm{P}$ & 2 & $2.26 \pm 0.02$ & $0.048 \pm 0.005$ & & & \\
\hline & & $\mathrm{Ru}-\mathrm{Cl}$ & 2 & $2.41 \pm 0.02$ & $0.065 \pm 0.007$ & & & \\
\hline & \multirow[t]{3}{*}{ Embedded } & $\mathrm{Ru}-\mathrm{N}$ & 2 & $2.18 \pm 0.02$ & $0.050 \pm 0.005$ & \multirow[t]{3}{*}{23.27} & \multirow[t]{3}{*}{$3.0-15.0$} & \multirow[t]{3}{*}{23.61} \\
\hline & & $\mathrm{Ru}-\mathrm{P}$ & 2 & $2.25 \pm 0.02$ & $0.050 \pm 0.005$ & & & \\
\hline & & $\mathrm{Ru}-\mathrm{Cl}$ & 2 & $2.41 \pm 0.03$ & $0.067 \pm 0.008$ & & & \\
\hline
\end{tabular}

a Absorber (A)-backscatterers (Bs); ${ }^{\mathrm{b}}$ coordination number $N$; ${ }^{\mathrm{c}}$ interatomic distance $r$; ${ }^{\mathrm{d}}$ Debye-Waller factor $\sigma$ with its calculated deviation; and ${ }^{\mathrm{e}}$ shift of the threshold energy $\Delta E_{0}$. 


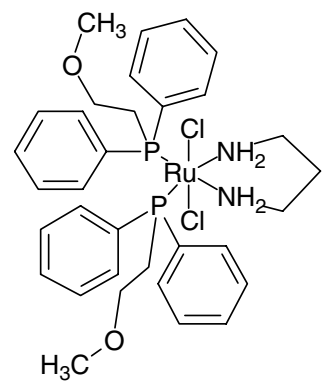

4

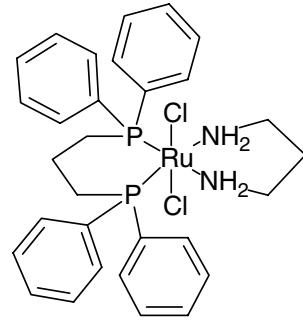

5

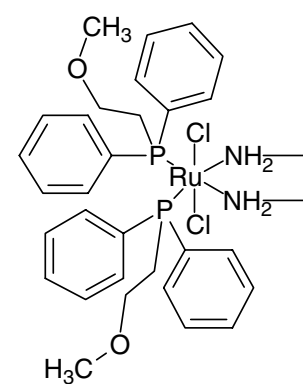

6

Figure 5. Structure of ruthenium(II) complexes $\mathbf{4 , 5}$ and $\mathbf{6}$ (with different ligands).
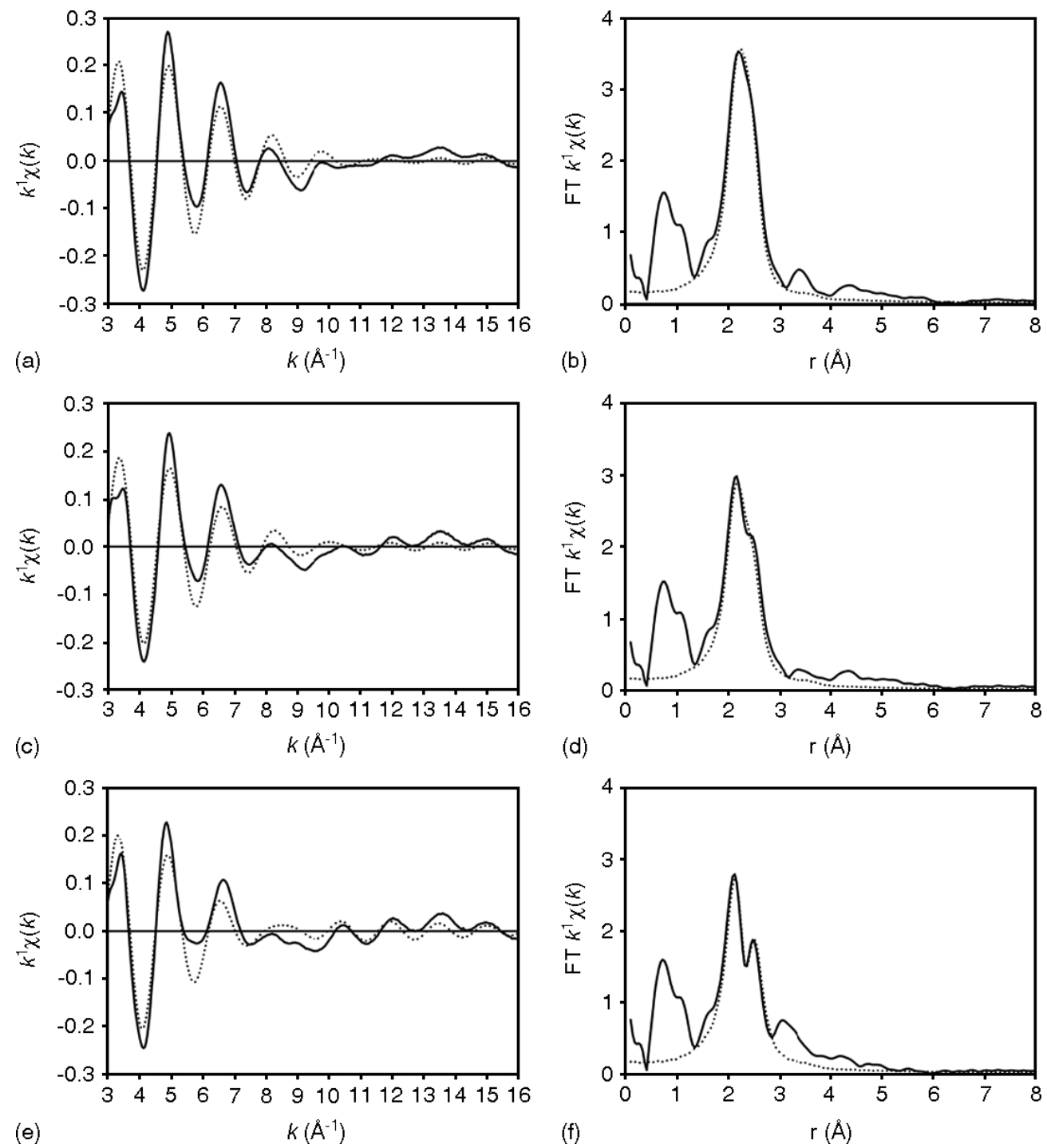

Figure 6. Experimental (solid line) and calculated (dotted line) EXAFS functions and their Fourier transforms for complexes 4 (a and b), 5 (c and d) and $\mathbf{6}$ (e and f).

mentioned in literature. ${ }^{29}$ The experimentally determined and theoretically calculated EXAFS functions in $k$-space and their Fourier transforms in real space for the complexes 4,

Copyright $@ 2007$ John Wiley \& Sons, Ltd.
5 and 6, measured at Ru K-edge, are shown in Fig. 6. The EXAFS determined structural parameters are summarized in Table 2. In addition, the experimentally determined Fourier 
Table 2. EXAFS determined structural parameters for complexes 4-6

\begin{tabular}{llcccccc}
\hline Complex & $\mathrm{A}-\mathrm{Bs}^{\mathrm{a}}$ & $N^{\mathrm{b}}$ & $r^{\mathrm{c}}[\AA]$ & $\sigma^{\mathrm{d}}[\AA]$ & $E_{\mathrm{F}}^{\mathrm{e}}[\mathrm{eV}]$ & $k$-range $\left[\AA^{-1}\right]$ & $R$-factor \\
\hline $\mathbf{4}$ & $\mathrm{Ru}-\mathrm{N}$ & 2 & $2.21 \pm 0.02$ & $0.059 \pm 0.006$ & 6.354 & $2.98-16.03$ & 43.20 \\
& $\mathrm{Ru}-\mathrm{P}$ & 2 & $2.29 \pm 0.02$ & $0.050 \pm 0.005$ & & & \\
& $\mathrm{Ru}-\mathrm{Cl}$ & 2 & $2.40 \pm 0.03$ & $0.055 \pm 0.007$ & & & 48.21 \\
$\mathbf{5}$ & $\mathrm{Ru}-\mathrm{N}$ & 2 & $2.23 \pm 0.02$ & $0.084 \pm 0.008$ & 7.020 & $2.98-16.04$ & 50.11 \\
& $\mathrm{Ru}-\mathrm{P}$ & 2 & $2.28 \pm 0.02$ & $0.050 \pm 0.005$ & & & \\
$\mathbf{6}$ & $\mathrm{Ru}-\mathrm{Cl}$ & 2 & $2.40 \pm 0.03$ & $0.063 \pm 0.008$ & & & \\
& $\mathrm{Ru}-\mathrm{N}$ & 2 & $2.19 \pm 0.02$ & $0.077 \pm 0.008$ & 5.051 & $2.98-16.02$ & \\
& $\mathrm{Ru}-\mathrm{P}$ & 2 & $2.28 \pm 0.02$ & $0.050 \pm 0.005$ & & & \\
& $\mathrm{Ru}-\mathrm{Cl}$ & 2 & $2.44 \pm 0.03$ & $0.063 \pm 0.008$ & & & \\
\end{tabular}

a Absorber (A)-backscatterers (Bs); ${ }^{\mathrm{b}}$ coordination number $N$; ${ }^{\mathrm{c}}$ interatomic distance $r$; ${ }^{\mathrm{d}}$ Debye-Waller factor $\sigma$ with its calculated deviation; and ${ }^{\mathrm{e}}$ Fermi energy $E_{\mathrm{F}}$.

Table 3. AXAFS determined parameters compared with the electronegativity values

\begin{tabular}{|c|c|c|c|c|c|c|c|c|c|}
\hline Complex & $\begin{array}{c}r \text {-Range } \\
{[\AA]}\end{array}$ & $\begin{array}{c}\text { Peak } \\
\text { position }[\AA]\end{array}$ & Intensity & $\begin{array}{c}\text { Overall } \\
\text { area }\left[\AA^{2}\right]\end{array}$ & Neighbors & EN & $N$ & $\begin{array}{c}\text { Overall } \\
\text { EN }\end{array}$ & $\begin{array}{l}\text { Sum } \\
\text { EN }\end{array}$ \\
\hline 4 & $0.41-1.34$ & $\begin{array}{l}0.74 \\
1.07\end{array}$ & $\begin{array}{l}1.57 \\
1.09\end{array}$ & 0.9434 & $\begin{array}{l}\mathrm{N} \\
\mathrm{P} \\
\mathrm{Cl}\end{array}$ & $\begin{array}{l}3.0 \\
2.1 \\
3.0\end{array}$ & $\begin{array}{l}2 \\
2 \\
2\end{array}$ & $\begin{array}{l}6.0 \\
4.2 \\
6.0\end{array}$ & 16.2 \\
\hline 5 & $0.41-1.34$ & $\begin{array}{l}0.74 \\
1.07\end{array}$ & $\begin{array}{l}1.52 \\
1.09\end{array}$ & 0.9313 & $\begin{array}{l}\mathrm{N} \\
\mathrm{P} \\
\mathrm{Cl}\end{array}$ & $\begin{array}{l}3.0 \\
2.1 \\
3.0\end{array}$ & $\begin{array}{l}2 \\
2 \\
2\end{array}$ & $\begin{array}{l}6.0 \\
4.2 \\
6.0\end{array}$ & 16.2 \\
\hline 6 & $0.41-1.34$ & $\begin{array}{l}0.72 \\
1.07\end{array}$ & $\begin{array}{l}1.61 \\
1.06\end{array}$ & 0.9541 & $\begin{array}{l}\mathrm{N} \\
\mathrm{P} \\
\mathrm{Cl}\end{array}$ & $\begin{array}{l}3.0 \\
2.1 \\
3.0\end{array}$ & $\begin{array}{l}2 \\
2 \\
2\end{array}$ & $\begin{array}{l}6.0 \\
4.2 \\
6.0\end{array}$ & 16.2 \\
\hline
\end{tabular}

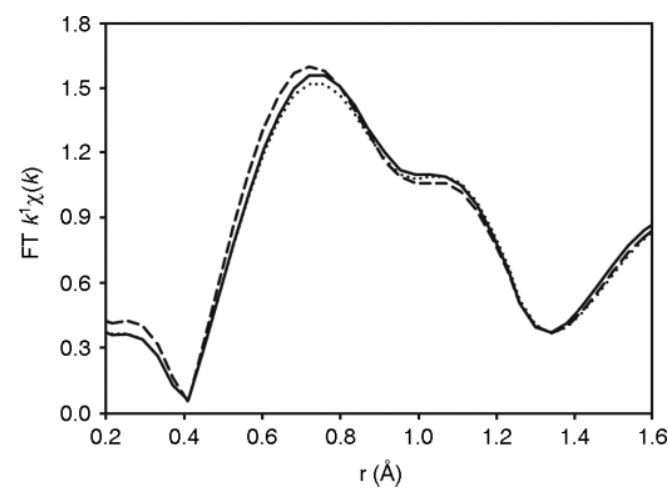

Figure 7. Experimentally determined Fourier transforms of the AXAFS spectra of complexes $\mathbf{4}$ (solid line), $\mathbf{5}$ (dotted line) and $\mathbf{6}$ (dashed line), measured at Ru K-edge.

transforms illustrating the AXAFS features are shown in Fig. 7. Since the polarization of the absorbing atom can be correlated with electronegativity (EN) of the neighboring atoms, the AXAFS determined parameters are compared with the sum of the electronegativity values of the neighboring atoms in Table 3.<smiles>COCc1ccccc1P(c1ccccc1)P(c1ccccc1)(c1ccccc1)(c1ccccc1)C(N)(N)CC(c1ccccc1)c1ccccc1</smiles><smiles>NC(Cl)(CC(c1ccccc1)c1ccccc1)P(c1ccccc1)(c1ccccc1)(c1ccccc1)c1ccccc1</smiles>

Figure 8. Structure of ruthenium(II) complexes $\mathbf{7}$ and $\mathbf{8}$.

The EXAFS determined structural parameters are in accordance with the values determined using single crystal X-ray diffraction for the respective complexes. ${ }^{19,20}$ In the AXAFS spectra, even though no remarkable changes could be observed in the peak shapes and positions (emphasizing that the local structure around the ruthenium nucleus is the same in all the three cases), changes could be observed in the AXAFS intensity (quantified by FT area) between the complexes with different ligands, which could be attributed 
to the changes in the electron density around the ruthenium atom.

Complexes 4 and 5 have nearly the same structure; the only difference is that the complex 4 has an ether-phosphine ligand, whereas the complex 5 has a diphosphine ligand. As a result, these two complexes have different electronic structure around the central ruthenium atom, as revealed by AXAFS. The observed differences in the electronic properties can be correlated with the catalytic activity of these two complexes (4 and 5). In the selective hydrogenation of trans-4-phenyl-3-butene-2-one, complex 4 yields $80 \%$ of trans-4-phenyl-3-butene-2-ol and 20\% of 4-phenyl-2-butanol, whereas complex 5 yields $100 \%$ of trans-4-phenyl-3-butene2-ol. ${ }^{19,20}$ The AXAFS studies indicate that the polarization of the absorbing atom by the neighbors (including far atoms) is due to space field effects, where the transmission of charge takes place through space due to the intramolecular columbic interaction between the active metal center and a remote unipole or dipole.

\section{Role of co-catalyst in asymmetric transfer hydrogenation reaction}

The diamine(ether-phosphine) (7) and diamine(diphosphine) (8) ruthenium(II) complexes, depicted in Fig. 8, were used to examine the role of co-catalyst in determining the structure of catalytic intermediate species in the asymmetric transfer hydrogenation reaction. The reaction of these complexes with ${ }^{t} \mathrm{BuOK}$ was performed by dissolving the complex in 2-propanol, which serves as the conventional hydrogen source. EXAFS spectroscopic measurements were performed on the complexes prior to the reaction, after dissolution in 2-propanol and after the addition of the co-catalyst, ${ }^{t} \mathrm{BuOK}$, to the dissolved complex. The experimentally determined and theoretically calculated EXAFS functions in $k$-space and the
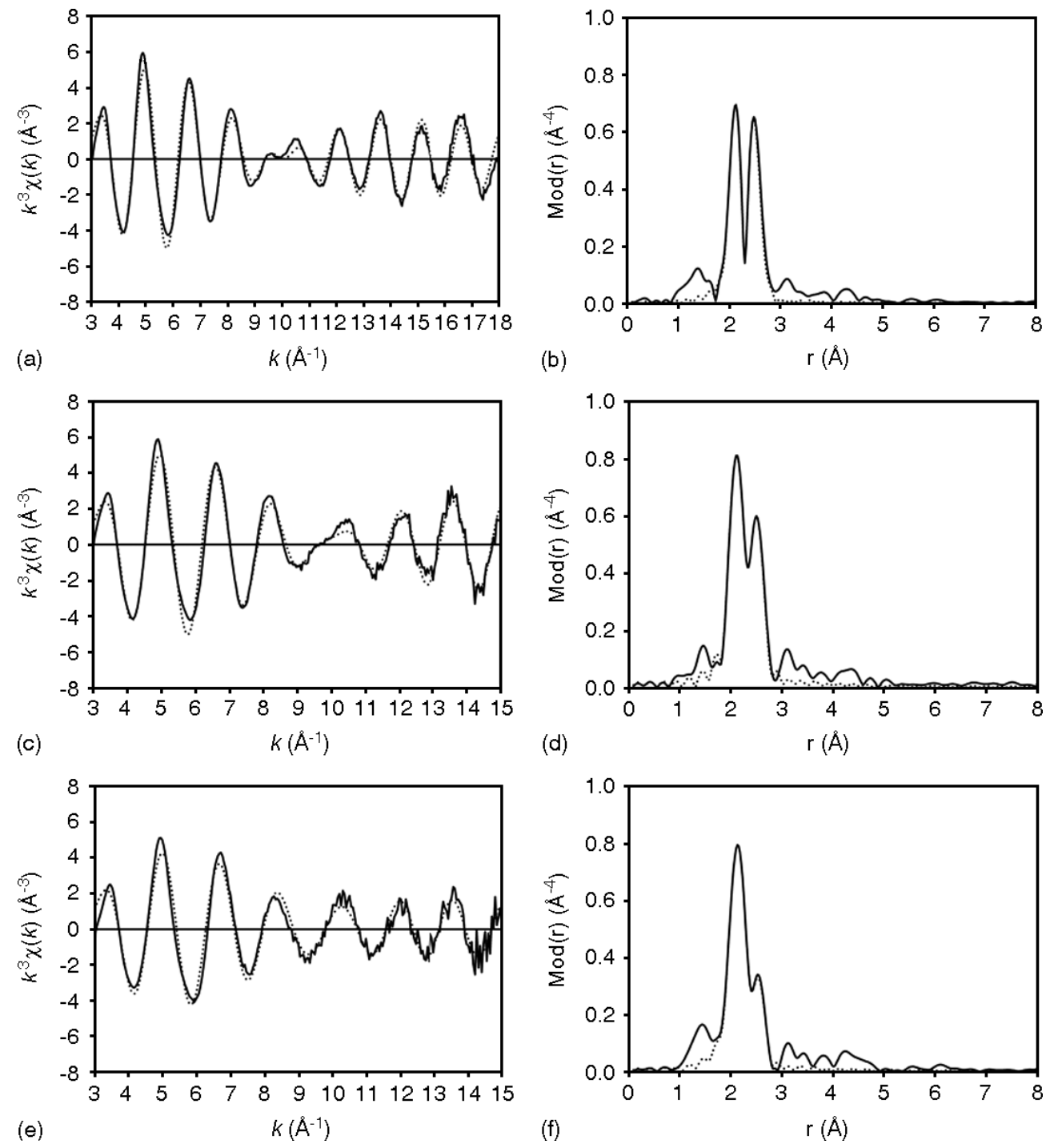

Figure 9. Experimental (solid line) and calculated (dotted line) EXAFS functions and their Fourier transforms of complex 7 before reaction ( $\mathrm{a}$ and $\mathrm{b}$ ), after dissolution in 2-propanol (c and $\mathrm{d}$ ) and after addition of ${ }^{t} \mathrm{BuOK}$ to the dissolved complex (e and $\mathrm{f}$ ). 
corresponding Fourier transforms in real space for complex 7 before the reaction, after dissolution in 2-propanol and after addition of ${ }^{t} \mathrm{BuOK}$ to the dissolved complex, measured at $\mathrm{Ru}$ K-edge are shown in Fig. 9. The obtained structural parameters are summarized in Table 4.

The analysis of the data shows the influence of the cocatalyst on the coordination geometry around the ruthenium center. The $k^{3}$-weighted EXAFS function was described best by three different shells similar to the earlier cases. As it can be derived from the Fourier transforms, the nitrogen and phosphorous shells give rise to only one intense peak, but their contribution to the EXAFS function is significant. The other peak attributable to the chlorine shell is more sensitive to the co-catalyst. For complex 7 before reaction, two nitrogen backscatterers at $2.17 \AA$, two phosphorous backscatterers at $2.27 \AA$, and two chlorine backscatterers at $2.42 \AA$ could be determined, which are in good agreement with the values obtained from single crystal X-ray diffraction. ${ }^{19}$ The structure remained almost unaltered after dissolution in 2-propanol. However, when the co-catalyst ${ }^{t} \mathrm{BuOK}$ was added to the

Table 4. EXAFS determined structural parameters for complex $\mathbf{7}$

\begin{tabular}{|c|c|c|c|c|c|c|c|}
\hline Case & $\mathrm{A}-\mathrm{Bs}^{\mathrm{a}}$ & $N^{\mathrm{b}}$ & $r^{c}[\AA]$ & $\sigma^{\mathrm{d}}[\AA]$ & $\Delta E_{0}{ }^{\mathrm{e}}[\mathrm{eV}]$ & $k$-range $\left[\AA^{-1}\right]$ & $R$-factor \\
\hline \multirow[t]{3}{*}{ Before reaction } & $\mathrm{Ru}-\mathrm{N}$ & 2 & $2.17 \pm 0.02$ & $0.050 \pm 0.005$ & \multirow[t]{3}{*}{22.26} & \multirow[t]{3}{*}{$3.0-18.0$} & \multirow[t]{3}{*}{22.06} \\
\hline & $\mathrm{Ru}-\mathrm{P}$ & 2 & $2.27 \pm 0.02$ & $0.067 \pm 0.007$ & & & \\
\hline & $\mathrm{Ru}-\mathrm{Cl}$ & 2 & $2.42 \pm 0.03$ & $0.054 \pm 0.006$ & & & \\
\hline \multirow[t]{2}{*}{ After dissolution in 2-propanol } & $\mathrm{Ru}-\mathrm{N}$ & 2 & $2.17 \pm 0.02$ & $0.050 \pm 0.005$ & \multirow[t]{2}{*}{22.49} & \multirow[t]{2}{*}{$3.0-15.0$} & \multirow[t]{2}{*}{20.68} \\
\hline & $\mathrm{Ru}-\mathrm{P}$ & 2 & $2.27 \pm 0.02$ & $0.059 \pm 0.006$ & & & \\
\hline \multirow[t]{3}{*}{ After addition of ${ }^{t} \mathrm{BuOK}$} & $\mathrm{Ru}-\mathrm{N}$ & 2 & $2.15 \pm 0.02$ & $0.067 \pm 0.007$ & \multirow[t]{3}{*}{22.73} & \multirow[t]{3}{*}{$3.0-15.0$} & \multirow[t]{3}{*}{29.47} \\
\hline & $\mathrm{Ru}-\mathrm{P}$ & 2 & $2.30 \pm 0.02$ & $0.074 \pm 0.007$ & & & \\
\hline & $\mathrm{Ru}-\mathrm{Cl}$ & 1 & $2.43 \pm 0.03$ & $0.050 \pm 0.006$ & & & \\
\hline
\end{tabular}

a Absorber (A)-backscatterers (Bs); ${ }^{\mathrm{b}}$ coordination number $N$; ${ }^{\mathrm{c}}$ interatomic distance $r$; ${ }^{\mathrm{d}}$ Debye-Waller factor $\sigma$ with its calculated deviation; and ${ }^{\mathrm{e}}$ shift of the threshold energy $\Delta E_{0}$.
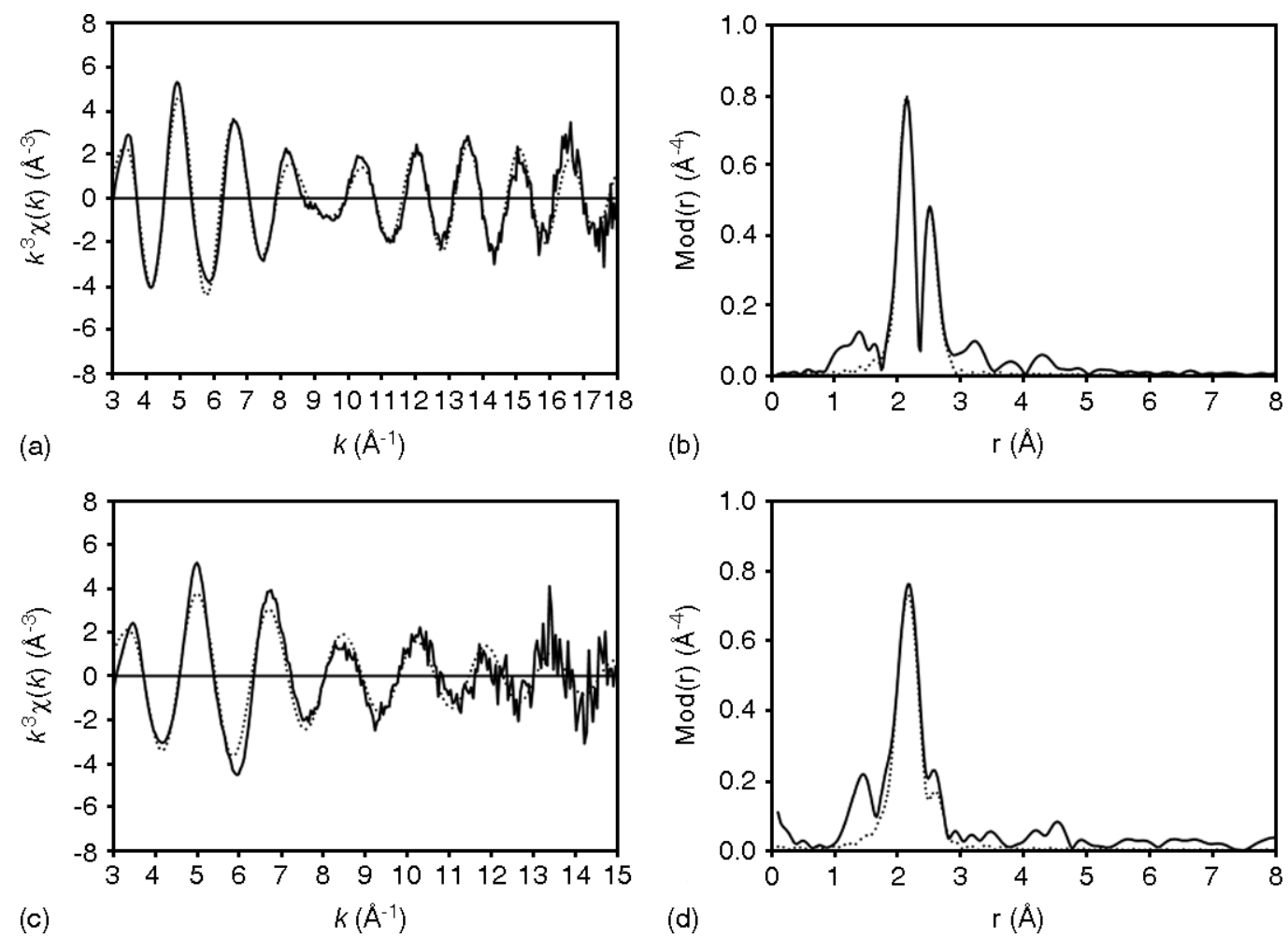

Figure 10. Experimental (solid line) and calculated (dotted line) EXAFS functions and their Fourier transforms of complex 8 before reaction ( $a$ and $b$ ) after addition of ${ }^{t} \mathrm{BuOK}$ to the complex dissolved in 2-propanol (c and d). 
Table 5. EXAFS determined structural parameters for complex $\mathbf{8}$

\begin{tabular}{|c|c|c|c|c|c|c|c|}
\hline Case & $\mathrm{A}-\mathrm{Bs}^{\mathrm{a}}$ & $N^{\mathrm{b}}$ & $r^{\mathrm{c}}[\AA]$ & $\sigma^{\mathrm{d}}[\AA]$ & $\Delta E_{0}{ }^{\mathrm{e}}[\mathrm{eV}]$ & $k$-range $\left[\AA^{-1}\right]$ & $R$-factor \\
\hline \multirow[t]{3}{*}{ Before reaction } & $\mathrm{Ru}-\mathrm{N}$ & 2 & $2.17 \pm 0.02$ & $0.050 \pm 0.005$ & \multirow[t]{3}{*}{21.78} & \multirow[t]{3}{*}{$3.0-18.0$} & \multirow[t]{3}{*}{25.04} \\
\hline & $\mathrm{Ru}-\mathrm{P}$ & 2 & $2.26 \pm 0.02$ & $0.060 \pm 0.006$ & & & \\
\hline & $\mathrm{Ru}-\mathrm{Cl}$ & 2 & $2.42 \pm 0.03$ & $0.063 \pm 0.006$ & & & \\
\hline \multirow[t]{2}{*}{ After addition of ${ }^{t} \mathrm{BuOK}$} & $\mathrm{Ru}-\mathrm{N}$ & 2 & $2.15 \pm 0.02$ & $0.077 \pm 0.008$ & \multirow[t]{2}{*}{23.16} & \multirow[t]{2}{*}{$3.0-15.0$} & \multirow[t]{2}{*}{38.74} \\
\hline & $\mathrm{Ru}-\mathrm{P}$ & 2 & $2.30 \pm 0.02$ & $0.077 \pm 0.008$ & & & \\
\hline
\end{tabular}

${ }^{\mathrm{a}}$ Absorber (A) - backscatterers (Bs); ${ }^{\mathrm{b}}$ coordination number $N ;{ }^{\mathrm{c}}$ interatomic distance $r{ }^{\mathrm{d}}$ Debye-Waller factor $\sigma$ with its calculated deviation; and ${ }^{\mathrm{e}}$ shift of the threshold energy $\Delta E_{0}$.

solution of 7 in 2-propanol, structural changes could be noticed. It is interesting to observe the abstraction of only one of the two chlorine atoms bonded to the metal. Furthermore, the formation of $\mathrm{Ru}-\mathrm{O}$ species could not be evidenced from the EXAFS analysis. These results suggest the formation of a monochlorinated ruthenium(II) complex as an intermediate species.

In order to further validate the proposed results, the same reaction was studied with diamine(diphosphine) ruthenium(II) complex 8 . The experimentally determined and theoretically calculated EXAFS functions in $k$-space and the corresponding Fourier transforms in real space for complex 8 , before reaction and after the addition of ${ }^{t} \mathrm{BuOK}$ to the complex dissolved in 2-propanol, measured at Ru K-edge are shown in Fig. 10. The structural parameters are tabulated in Table 5.

Similar to the results obtained for complex 7, complex 8 also reveals the abstraction of a single chlorine in the course of the reaction when ${ }^{t} \mathrm{BuOK}$ was added to the complex dissolved in 2-propanol. In addition, the formation of $\mathrm{Ru}-\mathrm{O}$ species could not be evidenced in this complex as well. These results illustrate the formation of a monochlorinated complex as an intermediate species in the asymmetric hydrogenation reaction and also demonstrate the leading role played by the co-catalyst in influencing the structure of this intermediate species.

\section{CONCLUSIONS}

The EXAFS investigations indicate that the catalytically active ruthenium(II) complexes retain their structural integrity when they are embedded on polysiloxane matrices to form stationary phase materials. The variations in the catalytic activity of the complexes with different ligands can be correlated to the differences observed in the electronic structure around the active ruthenium center, probed by means of AXAFS studies. In addition, the investigations reveal that the co-catalyst plays a crucial role not only in enhancing the catalytic activity but also in determining the structure of the intermediate species. It is significant to note that, from the two chlorine atoms bonded to the ruthenium metal center, only one chlorine atom is abstracted during the reaction of the complex with the co-catalyst.

\section{Acknowledgments}

The financial support for this work by Deutsche Forschungsgemeinschaft (DFG) in the framework of a graduate college on 'Chemistry in Interphases' is gratefully acknowledged. We thank Professor E. Lindner and his co-workers at the Institute of Inorganic Chemistry, University of Tuebingen, Tuebingen for the provision of the samples. HASYLAB at DESY, Hamburg is acknowledged for providing synchrotron radiation for the XAFS spectroscopic measurements.

\section{REFERENCES}

1. Cornils B, Hermann WA (eds). Applied Homogeneous Catalysis with Organometallic Compounds. Wiley VCH: Weinheim, 1996.

2. Lindner E, Schneller T, Auer F, Mayer HA. Angew. Chem. Int. Edn 1999; 38: 2154.

3. Lindner E, Al-Gharabli S, Warad I, Mayer HA, Steinbrecher S, Plies E, Seiler M, Bertagnolli H. Z. Anorg. Allg. Chem. 2003; 629: 161.

4. Lindner E, Salesch T, Brugger S, Steinbrecher S, Plies E, Seiler M, Bertagnolli H, Mayer HA. Eur. J. Inorg. Chem. 2002; 1998.

5. Lindner E, Al-Gharabli S, Mayer HA. Inorg. Chim. Acta 2002; 334: 113

6. Lindner E, Ghanem A, Warad I, Eichele K, Mayer HA, Schurig V. Tetrahedron: Asymmetry 2003; 14: 1045.

7. Ohkuma T, Ooka H, Hashiguchi S, Ikariya T, Noyori R. J. Am. Chem. Soc. 1995; 117: 2675.

8. Ohkuma T, Ooka H, Ikariya T, Noyori R. J. Am. Chem. Soc. 1995; 117: 10417.

9. Noyori R, Ohkuma T. Angew. Chem. Int. Edn 2001; 40: 40.

10. Yamakawa M, Ito H, Noyori R. J. Am. Chem. Soc. 2000; 122: 1466.

11. Ohkuma T, Takeno H, Honda Y, Noyori R. Adv. Synth. Catal. 2001; 343: 369.

12. Noyori R, Yamakawa M, Hashiguchi S. J. Org. Chem. 2001; 66: 7931.

13. Teo BK. EXAFS: Basic Principles and Data Analysis. Springer: Berlin, 1986.

14. Koningsberger DC, Prins R (eds). X-ray Absorption: Principles, Applications, Techniques of EXAFS, SEXAFS and XANES. Wiley: New York, 1988.

15. Holland BW, Pendry JB, Pettifer RF, Bordas J. J. Phys. C 1978; 11: 633.

16. van der Eerden AMJ, Visser T, Nijhuis TA, Ikeda Y, Lepage M, Koningsberger DC, Weckhuysen BM. J. Am. Chem. Soc. 2005; 127: 3272. 


\section{OC Materials, Nanoscience and Catalysis}

17. Hartmann KR, Chen P. Angew. Chem. Int. Edn 2001; 40: 3581.

18. Noyori R. Angew Chem. Int. Edn 2002; 41: 8.

19. Lindner E, Warad I, Eichele K, Mayer HA. Inorg. Chim. Acta 2003; 350: 49.

20. Lindner E, Mayer HA, Warad I, Eichele K. J. Organomet. Chem. 2003; 665: 176.

21. Salesch T, Bachmann S, Brugger S, Rabelo-Schaefer R, Albert K, Steinbrecher S, Plies E, Mehdi A, Reye C, Corriu RJP, Lindner E. Adv. Funct. Mater. 2002; 12: 134.

22. Corriu RJP, Hoarau C, Mehdi A, Reye C. Chem. Commun. 2000; 71.

23. Wu D, Marzini M, Lindner E, Mayer HA. Z. Anorg. Allg. Chem. 2005; 631: 2538.
24. Wu D, Lindner E, Mayer HA, Jiang Z, Krishnan V, Bertagnolli H. Chem. Mater. 2005; 17: 3951.

25. Ressler T. J. de Phys. IV 1997; C2-7: 269.

26. Newville M, Livins P, Yakoby Y, Rehr JJ, Stern EA. Phys. Rev. B 1993; 14126.

27. Gurman SJ, Binstead N, Ross I. J. Phys. C 1986; 19: 1845.

28. van Dorssen GE, Koningsberger DC, Ramaker DE. J. Phys. Condens. Matter 2002; 14: 13529.

29. Tromp M, Slagt MQ, Gebbink RJMK, van Koten G, Ramaker DE, Koningsberger DC. Phys. Chem. Chem. Phys. 2004; 6: 4397. 